IRA-International Journal of Education \&

Multidisciplinary Studies

ISSN 2455-2526; Vol.17, Issue o3 (Q3, 2021)

Pg. no. $130-142$.

IRA Academico Research

\title{
A Study of Junior High School English Writing Teaching Based on Scaffolding Theory
}

\section{Rong Wang}

Postgraduate in Yangtze University, Jingzhou, Hubei, 434000, P.R. China.

Type of Work: Peer Reviewed.

DOI: 10.21013/jems.v17.n3.p3

DOI URL: https://dx.doi.org/10.21013/jems.v17.n3.p3

\section{How to cite this paper:}

Wang, R. (2021). A Study of Junior High School English Writing Teaching Based on Scaffolding Theory. IRA-International Journal of Education \& Multidisciplinary Studies (ISSN 2455-2526), 17(3), 130-142. DOI: https://dx.doi.org/10.21013/jems.v17.n3.p3

(C) IRA Academico Research.

(c) EY-NC This work is licensed under a Creative Commons Attribution-NonCommercial 4.0 International License subject to a proper citation to the publication source of the work.

Disclaimer: The scholarly papers as reviewed and published by IRA Academico Research are the views and opinions of their respective authors and are not the views or opinions of IRA Academico Research. IRA Academico Research disclaims any harm or loss caused due to the published content to any party.

IRA Academico Research is an institutional publisher member of Publishers International Linking Association Inc. (PILA-CrossRef), USA. IRA Academico Research is an institutional signatory to the Budapest Open Access Initiative. Hungary advocating the open access of scientific and scholarly knowledge. IRA Academico Research is a registered content provider under Open Access Initiative Protocol for Metadata Harvesting (OAl-PMH).

The journal is indexed \& included in WorldCat Discovery Service (USA), CrossRef Metadata Search (USA), WorldCat (USA), OCLC (USA), Open J-Gate (India), EZB (Germany) Scilit (Switzerland), Airiti (China), Bielefeld Academic Search Engine (BASE) of Bielefeld University, Germany, PKP Index of Simon Fraser University, Canada. 


\section{ABSTRACT}

Writing, as an important language skill, receives much attention in language teaching in junior high school. Traditional writing teaching always asks students to remember examples by heart to collect language resources, which plays no real function to improve students' writing skills. Thus, it is necessary to design the writing class in an effective way. This thesis aims to illustrate how to build scaffolding for students during the process approach to writing and help them complete the writing tasks. This method focuses on the process of building scaffolding to facilitate the writing process rather than only emphasizing the outcome. Through the classroom observation and cases analysis, the author further explores the scaffolding theory in English writing teaching in junior high school.

Key Words: scaffolding theory junior high school writing teaching

\section{Introduction}

Writing is an indispensable part of language skills, which is based on the other four skills: listening, speaking, reading and viewing, however, it is always ignored in English language classrooms in junior high school. Writing in the classroom is usually considered as a means to consolidate language that is recently studied and also called pseudo writing. Therefore, teacher's roles cannot be acted adequately and students cannot enjoy the writing process. Based on scaffolding theory, teachers provide chances for students to write in a certain context. Thus, learners will focus more on the process of writing and with the help of scaffolding they can write smoothly and independently.

With the help of scaffolding in language teaching, much progress of the researches at home and abroad has been made constantly. To have a more comprehensive outlook about the scaffolding theory, the author seeks to studies that have related topics over the past few decades. Many researchers illustrate how teachers help learners write effectively with the help of scaffolding. The following are some resources about scaffolding theory and writing elaborated in literature both from China and abroad.

Wood, Bruner \& Ross, in the article "The Role of Tutoring in Problem Solving” published in Journal of Child Psychology and Psychiatry in 1970 based on Constructivism and Vygotsky's "Zone of Proximal Development", mention that "scaffold" means the way that learners acquire the new language and it involves peers, teachers or other instructors in one's learning process. However, different scholars and educators define scaffold in various ways. But in fact, scaffolding is a kind of facilitator in writing.

Vygotsky, in his book Mind of Society: The Development of Higher Psychological Process published in 1978, points out that scaffolding instruction can be divided into five parts which are building scaffold, entering context, exploring independently, learning cooperatively and evaluating effects according to the concept of "Zone of Proximal Development". And the core concept of scaffolding is to put the students into center and the teacher plays the role of guidance. It also emphasizes the importance to create a real context for learners which can activate their minds.

In "Tools for Scaffolding Students in a Complex Learning Environment: What Have We Gained and What Have We Missed?" in Educational Psychologist published in 2014, the author explains the change notion of scaffolding. The article claims that how to apply scaffolding in English writing. It suggests that scaffolding can be removed when learners can finish the task independently.

Apart from the foreign researchers, much research about the practice of scaffolding theory in English writing occurs at home. In Wang Qiang's book A Course in English Language Teaching published in 2006, she holds that the process approach of writing should be given the focus on the process rather than a product. English writing can be divided into nine stages and each stage has its own aim. Therefore, learners will pay attention to how to expand their thinking instead of increasing their final mark of the product. 
Ren Shumei, in her journal "The Application of Scaffolding Theory in English Reading and Writing Teaching in Senior High School" published in Education for Chinese After-school in 2017, proposes that scaffolding theory is helpful to build systematic knowledge which can be used in the process of writing. In contrary to reading, the practice of scaffolding theory in writing is to decompose the difficult task into pieces and contribute them into more detailed parts. Then, learners can acquire systematic knowledge through recomposing. In fact, the exercise of English writing is to build an English learning system and at the same time, the level of writing skill will be improved.

Shi Dandan, in her thesis "How to Optimize English Writing Teaching in Junior High School by Scaffolding" published in Comparative Study of Cultural Innovation in 2017, illustrates how to proceed with the writing class. The scaffolding can be established in different stages such as in lesson planning of the class, in the process of writing class and the evaluation. She also stresses the importance of feedback to learners both from peers and the instructor.

Shu Qingxia, a front-line teacher who works in a junior high school in Zhejiang Province, puts forward the scaffolding as a basis that can improve writing skills in her thesis "A Study of English Writing Teaching in Junior High School Based on Scaffolding Theory" published in New Curriculum Research in 2018. At first, the teacher needs to give a three-dimensional analysis of the class, making clear language points and the stage of the class. Then, cooperation among students is considered as the foundation to activate learners' thoughts. Next, group work is highly prized as the main activity form in writing class which can make up the limitations of pair work. Also, the discussion is an essential part of writing that provides a smooth transition from thinking about how to write and increase communicative efficiency. At last, the teacher pays more attention to evaluation to reflect where still need improvements.

Yang Rongjie, in her thesis "The Application of Scaffolding Theory in Junior High School English Writing Teaching" which is published in Research on Curriculum and Teaching in 2019, indicates the importance to activate the students' minds before writing. She also points out that teachers can build scaffolding by theme vocabulary, changing the structure of sentences into complex forms and making use of idioms in English to promote writing. And the exemplified article is also helpful for students to facilitate the process of writing.

Xia Zhengmin, a first-line teacher in senior high school in Nanjing, in her article "A Study of English Reading and Writing in Senior High School Based on Scaffolding Theory" published in English Teachers in 2019, points out that writing as an output skill also promotes learning acquisition and the scaffolding will increase the degree of synergy between language input and output. It is necessary to help learners build emotional scaffolding so that there will be a clear goal to be achieved. Scaffolding can be built based on reading carefully, theme lead-in, fast reading and detailed reading contents. Besides, the language scaffolding can be built by new vocabulary acquisition and different assignments. At last, a certain context is created, in which the writing occurs in the macro surroundings that relax students.

With regard to scaffolding theory, Lu Jiping shows that speaking is the first step of writing in his thesis "The Exploration of English Writing Teaching in Junior High School Based on Scaffolding Theory" published in English Square in 2019. With the help of the interesting topics, learners will desire for expressing themselves and when learners speak loudly, they can write efficiently. English writing should be learner-centered so that students can receive supports from the scaffolding of sentence structure, expression manner and language skills and other aspects. Cooperation and communication among learners will give a certain and right direction for learners to write.

In order to collect more materials about the scaffolding theory in junior high school English writing teaching, the author went to three schools and attended the real classroom of many teachers. She also observed many typical classes online. This research is mainly qualitative, and some effective research tools are used in 
this thesis, such as classroom observation, interview, case analysis, etc. The thesis is mainly to research how to facilitate students' writing process based on scaffolding theory. It involves three chapters. The first chapter illustrates that how teachers build scaffolding to help students activate their background knowledge. The second chapter demonstrates how teachers promote students to write in their first draft based on scaffolding. The third chapter explores how teachers withdraw scaffolding to help students become independent writers in their final draft.

\section{The Stage of Activating Background Knowledge Based on Scaffolding Theory}

It is well-known that writing is a productive language skill based on students' prior knowledge. The product-oriented method only focuses on the final mark which could not develop students' writing skills effectively. Thus, the process approach to writing is highly praised recently, which begins with activating background knowledge. Therefore, this part mainly discusses what role does scaffolding play in activating students' background knowledge.

\subsection{Creating a Motivation to Write}

Writing in English teaching is always ignored as well as the process. However, the most effective teaching method is to ensure that our students want to write, know what to write and then how to write. Thus, creating a motivation to write is an indispensable step in the writing process especially for middle school students who are at a curious age. The context is related to students' daily life and the task-promoted or goal-oriented activities motivate students a lot to write.

The author observes a class of Grade 9 in a junior high school and records the whole process of this writing lesson-Colors and Moods. Miss Ma, female, is the English teacher of the class who always tries to design the class in a creative way to help students break the traditional logic and cultivate their abilities to imagine. There are 24 students in her class, who are divided into four groups and sit face to face with their group members. Most of them can express their own ideas in English smoothly although there are some mistakes in their pronunciation. The objectives of this class are divided into three levels. At the end of the class, students are expected to organize ideas about colours and moods, give details and reasons to support opinions, tell if a certain colour is proper for an advertisement and exemplify reasons and write a report on the relationship between colours and moods. At the very beginning, the teacher represents a travelling picture in Chongqing Monument of herself in red dress and asks students "Can you guess my mood from the colour I wear?" Almost the whole class put their hands up to answer the question. A girl is selected to reply, "I think you are happy because you are in red. And red represents happiness." Then, the teacher says, "Oh, yeah, I think so." and continues, "But I am a little nervous today". At the same time, she points at her sweater and asks students whether the red is a good choice today or not. One of the students gives advice that she would wear yellow because yellow represents success. Another one answers that she can wear blue because blue represents calmness. However, there is not enough time for the others who are active in class. Then, the teacher gives a general idea of the lead-in, "There are relationships between colours and moods, Right?"

In Miss Ma's class, she uses a photo of herself in Chongqiong Monument to create a real context. As students of Chongqiong, they are so familiar with Chongqiong Monument that they feel relaxed to start the new lesson. Furthermore, the teacher uses questions to enrich the context and attract students' interest because the topic inspires students to think and analyze the relation between colours and moods. The meaningful and interesting topic reminds students' background knowledge and helps them relate what they already knew to the writing topic. And it is obvious that all students are willing to join the class and want to express their ideas about the topic. Therefore, a relaxing environment stimulates students' curiosity and also makes a preparation for the 
next process. Students are motivated to write actively and the process of activating students' background knowledge provides a scaffolding for students to go on the following steps of the writing.

Another writing task is from an exam paper, and Miss Liu takes it as writing material for her class. To begin with, Miss Liu introduces Alice, a teenager who is upset, so she writes a letter about her problems. She tells that her parents focus too much attention on her grades, and set strict requirements about her online time. Then, the teacher makes clear the task that at the end of the lesson, students are required to reply to the letter, and give Alice some suggestions. Miss Liu shows some pictures which include typical parent-child problems and asks, "What are the problems between parents and teenagers?"The students answer eagerly and then Miss Liu classifies these problems.

Miss Liu assigns the final task for students at the very beginning, which is to write back and give some suggestions to Alice. This production-oriented task motivates students to think and write. In addition to the task, students are teenagers whose age is close to Alice, which stimulates students' emotion of caring about the same problems about themselves so that the topic resonates their own experience, giving students reasons and motivations to help Alice find out how to deal with the child-parents problems. Thus, the scaffolding is a built-in context to motivate students to focus on the topic and write with pleasure.

In short, both close-life contexts and production-oriented tasks can activate students' desire to write. High motivation promotes students to write willingly. It can be seen that only when students want to write at first, will they learn how to write.

\subsection{Brainstorming}

Brainstorming is a stage that students work together to brainstorm the ideas for writing as much as they can, and they have a record in detail to collect any material about the writing topic. Sometimes, brainstorming will be held through the form of discussion following some teachers' leading questions so that students not only can express their ideas freely but also can be inspired by others' sparkling points. Meanwhile, the teacher needs to ensure a reasonable grouping that encourages everyone in the group to join in the discussion actively and think about as much as they can. Teachers take advantage of examples or demons to expand students' minds and a chain of questions help students to associate ideas about the topic.

In the case of Miss Ma, she introduces a cinquain about colours and moods. At first, the teacher makes a cinquain and helps students analyze the structure and contents of the short poem, such as it involves the title, symbols, moods, opinions and conclusion. The teacher says, "You can restate the title and write the same one. You know the description between the colour and moods in your mind in this way. Would you work in your groups and share your ideas and write them down in your notebook?" While students are discussing, Miss Liu walks around the class and gives some prompts and encouragements like "You all think so? Good ideas and so on." All students talk about the topic heatedly and every group would like to share their short poems in front of the class.

In this case, Miss Ma writes a poem for students to imitate. The analysis of the structure and content in this cinquain gives students an excellent example so that they can write accordingly. Based on the demo, students are guided to express their ideas about moods and colours clearly, some of which can be involved in their writing directly. Brainstorming in small groups inspires students' different ideas about colours and moods, which bridges the information gap among the group's members. They discuss until getting the agreement. Thus, brainstorming aims to build a content scaffolding by helping students recall and expand their minds, which paves the way for the following writing procedures.

Another writing lesson, which takes the New century edition English book as its learning material, whose Lesson 1 of Unit 7 is 'What do you want to be?'. After introducing the topic to students, the teacher shows a 
public service advertising about Yao Ming, in which he plays many different occupations and then, revealing the theme that many people like Yao Ming in this video take various jobs. Then, the teacher asks students three questions to guide them to think. The first is what job Yaoming does in the video? The second is what do they want to do in the future? The third is how to become a good professional person? The task is writing a short passage about 'My Dream Job'. Then, the teacher organizes a discussion among students to talk about these questions.

In the second case, the teacher designs meaningful questions for students and guides them to explore the video step by step through these three questions. The questions chain builds scaffolding for students to think and associate. The first question takes students into the context. The second question helps students relate the writing topic to their own experiences. And the third question proposes a new aspect that students need to think about, which makes students reflect deeply about the topic. These questions not only avoid redundant teaching steps but focus students' attention on the theme and help them build a bridge between the writing topic and their imagination about a future career.

Therefore, brainstorming is an essential stage for writers to prepare the materials. With the teacher's guidance, students not only expand their minds but also prepare enough resources for the writing stage.

\subsection{Mapping}

Mapping is to help students organize their ideas in a logical and systematic way so that they can present a convincing argument. Different from brainstorming, which emphasizes the generation of new ideas related to the topic, mapping is a process to categorize the content for the passage so that students can write logically and coherently. Teachers help students build mind maps to form into structured knowledge, which helps students have a deeper understanding of the writing topic.

Miss Ma goes on her class by eliciting students to repeat the main ideas of the cinquain. She takes advantage of 4-square writing to provide a mapping for students to analyze the passage on the textbook: Millie's report about colours and moods. Miss Ma asks, "How does Millie describe colours and moods? Does she follow the four squares? Think about that." Students find out the corresponding content of each part of the four squares mapping. A boy answers that red represents power and strength. Miss Ma corrects, "About symbols?" The boy continues that white represents calmness and peace. Through a series of questions, students complete their mapping with corresponding content.

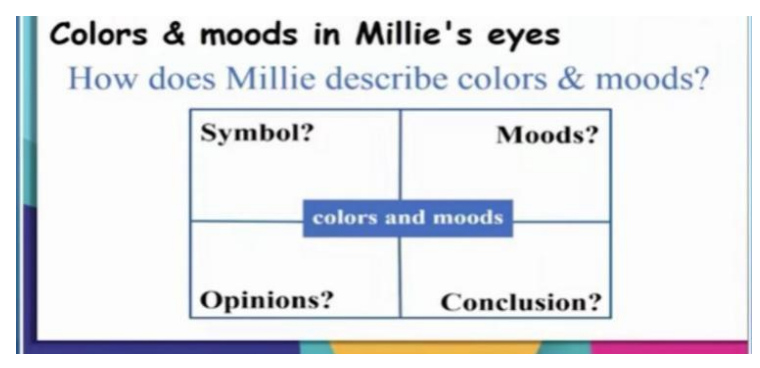

\section{(1c: Mapping Presented By Miss Ma)}

According to the above cases, Miss Ma helps students analyze the example based on 4-square writing so that they have a general idea and catch the characteristics of Millie's report. It can be found, under Miss Ma' guidance, students analyze the structure, find out the key information and finally construct structured knowledge. And Miss Ma focuses students' attention on the symbol which is the core concept of writing so that students can write around it logically and coherently. Thus, 4-square mapping plays a role to give students a transition scaffolding, helping students transit from collecting ideas to organize ideas smoothly. 
At the first stage, the major task of the teacher is to create a context for students, guide them to explore in the context, build scaffolding and learn cooperatively, such as organizing discussion to brainstorm, setting up mapping to organize ideas. It is a stage that the teacher provides more help or prompts to guide students to write. Thus, the teacher is supposed to build necessary and proper scaffolding, not too less, not too more. However, the teacher also needs to provide students with enough space to generate, produce and create.

After the observation of Miss Ma's class, the author has a short interview with Miss Ma and her students. Miss Ma talks to the author that at the stage of activating students' background knowledge, scaffolding plays an important role. With the help of scaffolding, such as nearly real context, a chain of questions and task-oriented activity and so on, students' interest and motivation are stimulated and their existed knowledge is activated. They are willing to get involved in the tasks, contribute their ideas and organize these ideas by using mind maps.

In conclusion, creating motivation, brainstorming and mapping are indispensable in the stage of activating students' background knowledge, as all of them are prepared for the next step of the first draft. The teacher gives various tasks or questions as future-oriented scaffolds which can get students to understand the writing topic.

\section{The Stage of Writing First Draft Based on Scaffolding Theory}

Good composition requires writers to focus on process, and the first draft provides a general structure and macro contents for writing. Thus, the first draft should be written down carefully instead of in a hurry. The process to write the first draft can be divided into three sub-stages, and each stage contributes to a good composition.

\subsection{Freewriting}

Following the mapping that the students organize in the last stage, freewriting refers that students write freely about the topic. Based on the mapping, students can expand the content, think about the coherence of the content and collect any ideas coming to their mind. It seems an inessential part, however, students can write anything on paper without interruption so that they can deliver whatever they want to express.

Before freewriting, Miss Ma guides students to pay attention to the characteristic of Millie's report and summarizes, "Actually we can find Millie's opinions easily, right? Because she states her opinion clearly." The phrase that states opinion "clearly" is highlighted in the red square as a rule of writing. Miss Ma says, "Having an opinion is a wonder, but how can we support them? How does Millie support her opinions? And now we go through her report and think about that." As a result, they conclude that opinions should be supported by details and reasons in writing, which is the second rule highlighted by a red square. Then, Miss Ma points out that colours may influence our choices by introducing two advertisements about juice and cellphone and asks that, "What do you think of the colours the model wears and his or her moods?" Then, students try to write colours and moods reflected in these advertisements freely based on the structure and main aspects from their mapping. Most of them write freely and develop their ideas smoothly.

As usual, teachers always overlook this stage and ask students to begin their writing following their commands. However, in this case, Miss Ma guides students to focus on the characteristics of text, conclude the writing rules from examples and states them clearly. It supports the requirements that students need to meet. It is a step that students explore and realize the rules by themselves so that they do not feel to be forced and accept them willingly. And the process of finding out the rules helps students understand how to obey these rules to complete their writing. These short rules are enough to lead students to write logically and coherently. It is the teacher's guidance that students write following rules. Thus, freewriting provides scaffolding helping students write following rules and establish a convincing argument. 


\subsection{Outlining}

If students have gathered enough ideas, a more detailed outline is created to illustrate the main structure and important points of the essay. Outlining is to present the main idea or the central topic of the passage. However, this stage encourages students to decide certain content for their own writing so that the scaffolding is built by students themselves. Thus, in the process approach to writing, the teacher's help as scaffolding is gradually removed.

After sharing the outcome of freewriting of several students, Miss Ma says that "Right now, why not write more detailed planning for your writing based on the four squares? Try to organize your ideas based on the four squares. You can write down the main ideas and keywords or phrases as supporting details. Ok, let's get started." While students are writing, Miss Ma goes around the class and asks two of them to write their outlines on the blackboard as the example to share with the others. There is an example of a students' outline.

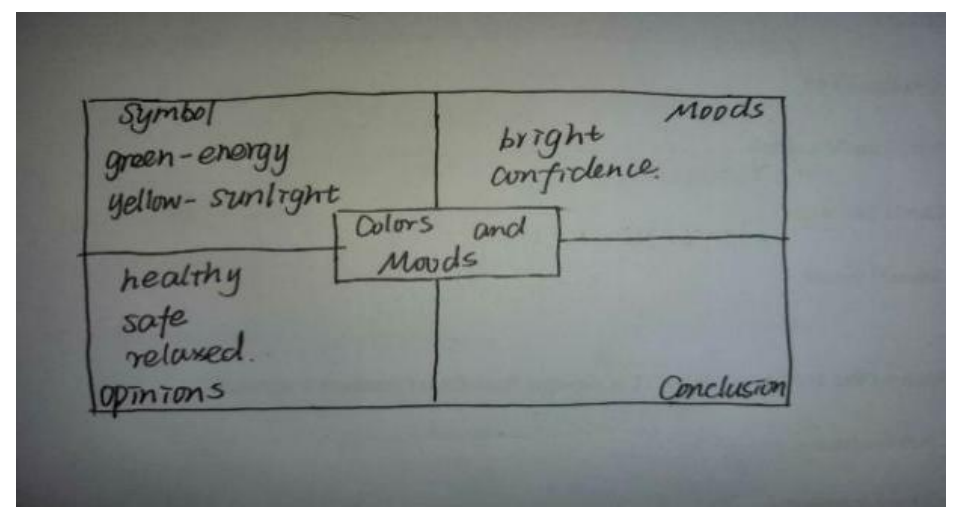

(2a: An Example of Astudents'Outline)

Outlining is the preparation for their first draft. According to the case, freewriting emphasizes putting their ideas on paper and develop fluency in writing. However, an outline helps students illustrate the main organizing structure and the most important points that decide the certain structure of their writing. Based on 4-square, students decide certain content of their writing such as keywords, topic sentences and notes for supporting details. An outline is the scaffolding that students build by themselves, which is the main structure of their own writing to avoid writing in digression.

\subsection{Drafting}

Outlining is the last procedure of the preparation for writing. Based on students' own outlines, they can begin to write. The former effort done by students lays the foundation for the first draft. Especially the teacher guides students to analyze the topic, enter the context, brainstorm the ideas, create the outline and so on, which can be seen as scaffolding helping students explore and write passages freely and independently.

In Miss Ma's class, she says, "I'm sure you cannot wait to write. But, let us think about that while drafting, we need to always think about these questions: Do I follow the 4-square? Do I state the opinion clearly? Do I give details or reasons to support opinions? Then, Miss Ma asks students to start writing. While students writing their first draft, Miss Ma walks around the classroom and asks students: "Do you have any problems?" However, no one has a problem so that Miss Ma goes on to pay attention to the content of their writing. 


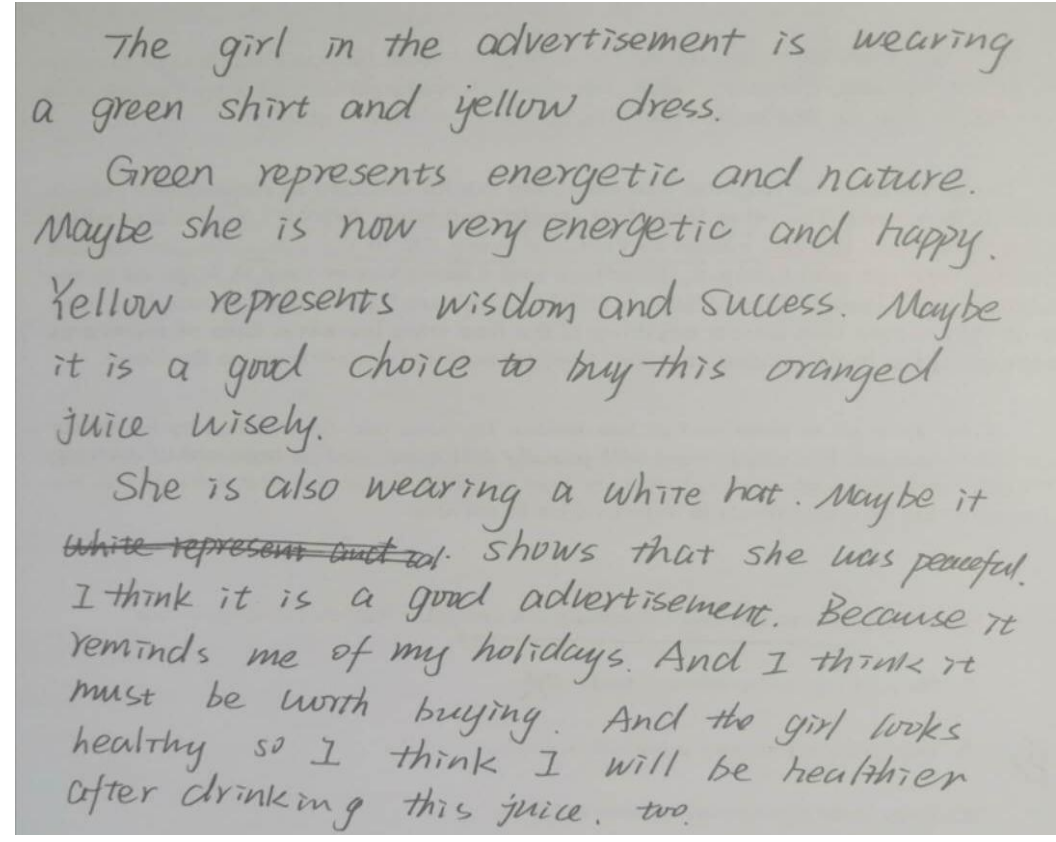

(2b: An Example of A students' Draft)

As can be seen in the students' writing, his mind is developed clearly following the 4-square writing. Based on his own outline, he expands his writing smoothly. It not only involves his opinions but also details and reasons to support his opinions. The sentence "Maybe it shows that she was peaceful because it reminds me of my holidays" is used to illustrate his ideas, which makes the passage convincing. The structure of his passage is in accordance with the minds that Miss Ma taught in the former steps. It shows that 4-square writing provides scaffolding for students and they can benefit a lot from it. Even though the teacher has begun to withdraw her assistance, students still can write and express themselves effectively.

At the end of class, the author has an interview with one of the students. She tells the author when she looks at the advertisement at first, she has no ideas about what to write. But following Miss Ma' guidance, she knows how to begin her passage. Besides, brainstorming and freewriting help her collect enough material and ideas and outlining organizes these ideas. Moreover, she learns how to give a clear demonstration and how to support it.

At the second stage of the class, the focus is on students. Teachers illustrate clear rules about how to write and support assistance when necessary but the major tasks are done by students. On the basis of the scaffolding theory, it is a stage that students explore independently, such as students can write down their different outlines and first draft. Teachers withdraw their assistance gradually and leave enough room for students to create and write based on their own opinions, thus, writing is authentic and meaningful. At the stage of writing the first draft, teachers guide students to write down their own outlines and start writing freely with the help of scaffolding. However, the teacher begins to withdraw her help to encourage students to complete the writing task independently and effectively.

\section{The Stage of Writing Final Draft Based on Scaffolding Theory}

The process approach to writing focuses on the writing process but the product is important as well. The process of writing the final draft involves three sub-stages, they are editing, revising and proofreading and each stage performs different functions. It is a stage that students complete their writing independently. 


\title{
4.1 Editing
}

According to Wang Qiang, "Editing is the stage when students read through their writings and check the clarity of ideas or the logical development of their arguments. Also, students check carefully the grammar, spelling and punctuation of their writing. Editing may take two forms: peer editing and self-editing." ${ }^{1}$ On the basis of editing, students not only improve their own writing but also benefit from their partner's writing. They can find out common problems and avoid them in their own writing. Thus, editing is a reciprocal step in helping students perfects their writing.

10 minutes later for drafting, Miss Ma asks a boy who would like to share his writing in front of the class to show his paper on the screen. To begin with, Miss Ma gives a demo about how to edit the boy's writing. She underlies the key sentences and says, 'Does he follow 4-square? Symbol? Yes, 'Green represents nature.' Moods? Does he write about moods? 'Maybe she is energetic and happy' Right? And what about opinions? 'I think it is a good advertisement' It's very clearly, right? At last, there is a conclusion part, right? Ok, guys, what about the details? There are some details or reasons in each paragraph." Then, Miss Ma presents the standards for editing on-screen and explains these criteria in detail. She says, "Please exchange your writing and begin to evaluate each other's writing carefully."

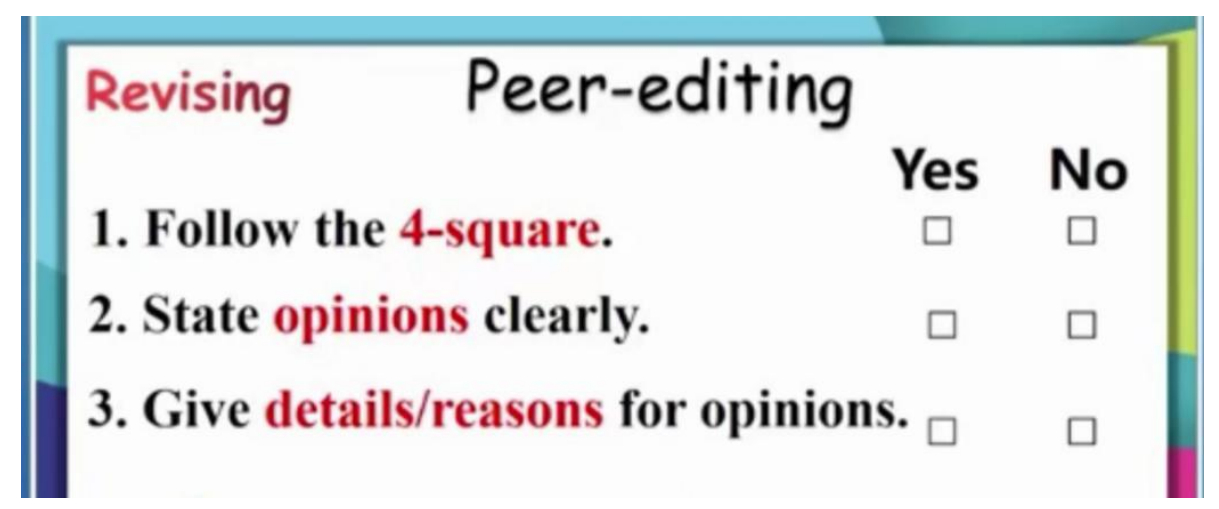

\author{
(3a: Rules Presented By Miss Ma)
}

One of the students says, "There are details and reasons supporting his opinions, such as the sentence 'Yellow represents wisdom and success." Moreover, some of them edit their partner's writing and gives some suggestions such as correct the first 'energetic' into 'energy'.

In the stage of editing, Miss Ma gives students a demo of how to edit. It is a scaffold to tell students the standards that should follow when editing. In this way, students know about how to evaluate and give useful suggestions. Students follow the standards to analyze others' writing and give some suggestions on the logical development, the reasons to support opinions and some careless mistakes. The standards provide detailed rules for students to edit, avoiding correct blindly and waste time. Peer-editing provides students not only opportunities to improve others' writing but also a sense of responsibility for their writing. Besides, they also get enlightenment from others and edit their own writing and improve and correct some parts. Therefore, editing is a reciprocal stage to perfect their writing.

\subsection{Revising}

According to A Course in English Language Teaching, "Revising is the stage when teachers guide students to make necessary improvements in both organization and contents based on either self-editing and peer-editing." ${ }^{2}$ Based on self-editing and peer-editing, students improve their own writing carefully. And the outcome of revision is the preparation for students to rewrite their final draft. 
IRA-International Journal of Education \& Multidisciplinary Studies

In this stage of Miss Ma's class, she concludes "Hey, guys. Do you know the secrets of perfect writing? Yeah, revising! Giving you and your partner's writing a revision and do not forget to choose one thing to polish. What tips can you offer?" At the same time, she passes each one a checklist and gives them 5 minutes to revise the different parts. For example, a student suggests to his partner, "You can reorder the development of your writing such as in the sentence 'Green represents nature. She wears a green shirt, which makes me feel comfortable.' Rewrite it as 'She wears green shirt makes me feel comfortable. And green represents nature. "”

Based on the example shown in the stage of drafting, the teacher also gives some advice about his passage. About the content, the writer can write more details that support more ideas about the relations between colours and moods, such as the colour of the model's skirt; what moods are reflected by her suit; what relation between the juice and the colour of her clothes. About the structure, Miss Ma gives advice as tell the reason, details and opinions clearly and gives more reasons to illustrate the opinions.

The stage of revising needs the teacher's advice or suggestion as a kind of scaffolding for their final draft. However, the importance of rewriting independently also cannot be ignored. The final draft approaches the end of the whole writing class and students learn how to revise the writing. Therefore, at this stage, language scaffolding, content scaffolding and so on are removed totally. Students can evaluate their writing and make improvements based on the scaffolding theory.

\subsection{Proofreading}

Proofreading is the last stage before the final draft, in which students are guided to read their own writing again carefully for any mistakes in grammar, spelling or capitalization. Actually, the process of proofreading is a completely independent process. Because students have familiarized them with their own writing, and it can help students form into good writing habits and develop their writing ability. Moreover, the teacher should limit his or her involvement in making the correction.

As it can be seen from Miss Ma's class, students' drafts are not very perfect which still involves some writing mistakes or notes of rewriting. Students need to proofread their writing carefully and correct any mistakes and complete clear, tidy and perfect writing as possible as they can. In the stage of proofreading, students can correct the mistakes by themselves and record them in order to avoid them next time. A teacher just supports a general evaluation or underlines those problematic items but students need to correct them by themselves. Here are some mistakes.

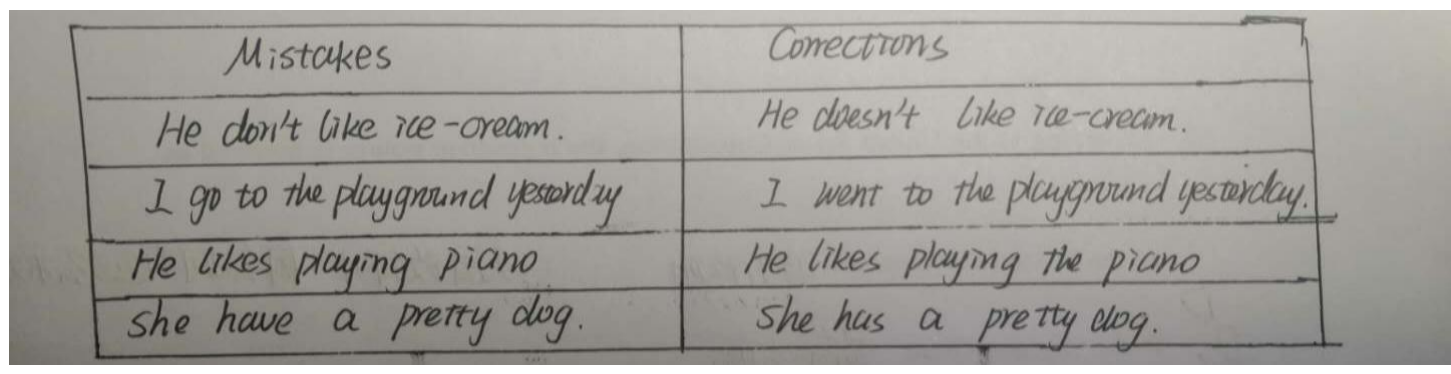

(3a: Some Mistakes )

Proofreading, as the last step before the final draft, is to exclude any mistakes. Students checking or correcting mistakes by themselves can not only develop the ability for future writing but also be aware of the standards about a good passage which brings enlightenment for them. And this stage is a sign that students can finish writing independently without scaffolding which is the original aim of the scaffolding theory. 
At the stage of a final draft, teachers only organize and proceed the class to the next step. Students finish a set of steps to improve their writing independently. It is the last stage to encourage students to write and become independent writers which are in accordance with the objectives of scaffolding theory. At last, Miss Ma adds a self-assessment for students to evaluate their learning process to help them learn better in the future.

After the class, the author has a short talk with one student whose passage is shown as an example in Miss Ma's class. He tells the author that at first, he is worried that his writing is not good enough to show in front of the class. But when he gets feedback from Miss Ma and his partner, he rewrites his passage easier. Besides, he knows where he should make some improvements and how to correct them. He thinks it is a helpful step to form into good writing habit in the process approach to writing.

Through editing, students improve the clarity of development of writing; through revising, they improve the organization and content of writing; through proofreading, they avoid any possible mistakes in their writing. Thus, it is a stage that students polish and perfects their writing.

\section{Conclusion}

The theory of scaffolding can date back to Social-constructivist theory and Vygotsky's Zone of Proximal Development. The aim of the scaffolding theory is to decompose difficult tasks for students and help them write independently and effectively. The process approach to writing is a popular writing module used in middle school, emphasizing putting students in the centre. And scaffolding in the writing process is to help students analyze topics, enter the context, explore independently, evaluate effectively and so on. The thesis is to illustrate how to practice scaffolding theory in the process approach to writing to improve students' writing ability.

Of course, scaffolding plays different roles in different stages and it could not exist through the whole writing process which will miss the original objective. The teacher's role is also changing during the writing process. At first, the teacher is a leader to help students know about the topic and enter the context. Then, the teacher is a facilitator to guide students to explore and write independently. At last, the teacher removes all scaffolding to encourage students to rewrite. In such a process, from building scaffolding to remove scaffolding, students know how to write a passage, know about the procedures to write, which is not only beneficial to develop their ability but also help them learn to write in reality.

In short, this thesis illustrates the whole class of Miss Ma, analyzes some related cases and puts forward some tentative enlightenment on how to improve English writing teaching based on scaffolding theory. It is expected that with the help of this thesis, English teachers use the scaffolding theory in their writing teaching to promote students writing effectiveness and independence so as to develop their writing ability. However, Because of limitations, this thesis cannot include the whole learning process and trace the period of learning based on scaffolding usage. And due to the author's view, there is not a comprehensive analysis of the benefits of the scaffolding theory as well as its deficiencies.

In order to improve English writing teaching in junior high school, it is necessary to research more. However, if the teacher learns how to combine theory and reality, the effectiveness of writing class can be improved a lot.

\section{References}

[1]. Puntambekar, S., \& Hübscher, R. (2005). Tools for scaffolding students in a complex learning environment: What have we gained and what have we missed? Educational Psychologist, 40, 1-12.

[2]. He Aijin.A Study on the Teaching of English Writing in Senior High Schools Based on Scaffolding Theory [J]. English Teacher. No. 3, 2020. 
[3]. Li Bing. Research on the teaching of combined reading and writing of English in junior high schools based on the "scaffolding" theory [D]. Chongqing Normal University, 2018.

[4]. Lu Jiping.A Probe into the Application of Scaffolding Teaching Model in Junior Middle School English Writ ing [J]. English Square, Issue 12, 2019.

[5]. Peng Yao. An Empirical Study on the Application of Scaffolding Theory in Junior Middle School English Wr iting Teaching [D]. Liaoning Normal University, 2016.

[6]. Ren Shumei.On the application of scaffolding theory in high school English reading and writing teaching. [J]. English world, 2017-12.

[7]. Shi Dandan. A brief talk on how to use scaffolding theory to optimize junior high school English writing teac hing [J]. A Comparative Study of Cultural Innovation, Issue 26, 2017.

[8]. Shu Qingxia. Research on English Writing Teaching in Junior Middle Schools Based on Scaffolding Teachin g [A]. New Exploration of Teaching Methods, Issue 4, 2018.

[9]. Vygotsky L. Mind of Society: The Development of Higher Psychological Process [ M]. Cambridge, MA, Harvard University Press, 1978.

[10]. Walqui, Aida. Scaffolding Instruction for English Language Learners: A Conceptual Framework [J]. International Journal of Bilingual Education and Bilingualism, 2006(6).

[11]. Wang Muyuan. Analysis of the teaching strategies of junior high school English writing based on core literac y [J]. Overseas English, Issue 3, 2020.

[12]. Wang Qiang. English Teaching Method Course [M]. Beijing: Higher Education Press, 2006.

[13]. William, Marion and Robert L. Burden. Psychology for Language Teachers: A Social Approach [M]. New York: Cambridge University Press, 1997.

[14]. Wood, Bruner, Ross. The Role of Tutoring Problem Solving [J]. Journal of Child Psychology and Psychiatry, 1976(8).

[15]. Xia Zhengmin. Research on high school English reading and writing teaching based on scaffolding teaching theory [J]. English Teacher, Issue 8, 2019.

[16]. Yang Rongjie.The application of scaffolding theory in the teaching of English writing in junior high schools [J]. Shanghai Curriculum Teaching Research, 2019.5.

[17]. Zhang Guorong. The application of "scaffolding" theory in English teaching [J]. Foreign Language and Foreign Language Teaching, Issue 9, 2004. 